\title{
Microstructural and Physical Properties of Thermoplastic Corn Starch/Polystyrene Blend Foams Affected by Different Contents and Combinations of Plasticizers
}

\author{
Amirreza Zabihi \\ Iran University of Science and Technology \\ Mohammad Fasihi ( $\sim$ mfasihi@iust.ac.ir) \\ Iran University of Science and Technology https://orcid.org/0000-0003-0362-118X \\ Sajad Rasouli \\ Iran University of Science and Technology
}

\section{Research Article}

Keywords: Thermoplastic Starch (TPS), Extrusion process, biodegradable polymer, foamability, microstructural and physical properties

Posted Date: June 17th, 2021

DOl: https://doi.org/10.21203/rs.3.rs-599880/v1

License: (c) (1) This work is licensed under a Creative Commons Attribution 4.0 International License. Read Full License

Version of Record: A version of this preprint was published at Journal of Polymers and the Environment on September 20th, 2021. See the published version at https://doi.org/10.1007/s10924-021-02293-1. 


\section{Abstract}

A comprehensive study was performed on thermoplastic corn starch (TPS)/polystyrene (PS) blend foam to optimize the formulation from the aspects of plasticizer content and the blend ratio. Plasticization of native starch was implemented with various contents of plasticizer (water + glycerol), 21, 23, 25 and 29\%, and water/glycerol ratio of $1 / 2,2 / 3,3 / 2$ and $2 / 1$ using melt extrusion process. The influence of plasticizer loading content and also its combination on the microstructural and physical properties of the blend foam were investigated. The morphological consideration was also carried out by scanning electron microscopy (SEM) to evaluate the distribution and regularity of the foam cells. In the following, full factorial method in Minitab software was used to optimize the formulation according to the properties. Moreover, the effect of PS content on the moisture absorption and cell structure of TPS/PS blend foam was evaluated. The addition of $20 \%$ PS to TPS caused to 6 times higher expansion ration than PS and $60 \%$ higher than TPS, while $50 \%$ lower moisture absorption than TPS. This combination can be a good alternative candidate for warm food packing applications.

\section{Introduction}

In the recent decades, many reports have shown an increased demand for plastic materials in various industrial and medical applications which have direct relationship with human health and the environment [1]. For example, plastic foams are widely used for diverse targets i.e. cushioning, insulation and warm food packaging [2]. Polystyrene (PS) is one of the most attractive plastics for foam industry, due to its low density, thermal insulation, good mechanical properties and low cost [3]. In spite of the desired properties, there are some challenges about the PS usage, i.e. that is indestructible, unsustainable and hazardous because of the release of toxic styrene, especially in hot applications [4]. Accordingly, many efforts were accomplished to replace the environmentally friendly or biodegradable polymers with PS by researchers [5-7]. In the recent years, starch as a bio-polymeric material from renewable resource attracted the attention of many researchers as a good candidate to alternate or blend with PS [8]. Starch has a low cost biodegradable, and can also be used into soil as a compost organic fertilizer [9].

Starch is a semi-crystalline polysaccharide with polyhedral shape that includes of a-(1-4)-linked Dglucose, amylose with a linear molecular architecture, and a highly branched amylopectin with the myriad points of a-(1-6)-linked branch [10]. Starch in its native state does not ability to process such as thermoplastic materials [11]. Therefore, to donate processability and flexibility to the starch, native starch has to transform to a moldable thermoplastic, thermoplastic starch (TPS)[12]. The homogeneous TPS melt is created via applying thermomechanical energy on native starch at the presence of water [13] and other plasticizers e.g. glycerol [14], poly(ethylene glycol) (PEG) [15], organic acids [16] and fatty acids [17]. In fact, the process leads to the reduction of intermolecular interactions between the starch chains, followed by the increment of the chains movements [18].

TPS foam manufactured by the extrusion-cooking technique, with various mechanical properties [19]. In general, TPS is blended with a synthetic polymer to improve the foamability, lowering the density and 
increasing the hydrophobicity of it [20]. So far, some studies were carried out to consider the influence of TPS on the TPS/PS blend foam properties[21-25] Pushpadass et al. [23] examined the effect of talc as a nucleating agent, azodicarbonamide (ADC) and citric acid as blowing agents on the properties of TPS/PS foam at different blend ratios. Their results showed that $0.5 \%$ talc increased expansion ratio of the foam, and citric acid led to a higher radial expansion and correspondingly lower density compared to ADC. Yayshahri, et al. [26] evaluated the effect of glycerol as a plasticizer on mechanical and degradation properties of high impact polystyrene (HIPS)/starch blend via melt extrusion process. According to their results, increasing the starch and glycerol caused a faster degradation rate, a decrease in the values of impact strength and softening point of the TPS/HIPS blend. Mihai et al. [24] measured the impact of glycerol on rheological properties of TPS/PS blend via in-line rheometry in an extrusion process. They founded that, the content of glycerol in TPS and also the TPS in the blend had a significant influence on the blend viscosity, and followed by on the blend foamability.

Despite a few researches on the TPS/PS blend foam, nevertheless, there is a lack of a comprehensive study into the plasticizer combinations effect on the physical properties and cell morphology of the foam. Factually, finding an optimized TPS to blend with PS at an efficient ratio is a very important issue which has not been considered yet. In this study, we investigated the impact of various plasticizer contents of water and glycerol at different water/glycerol ratio, and as well as the PS/TPS ratio on the microstructural properties, cell morphology and moisture absorption of the TPS/PS blend foams in continuous extrusion process.

\section{Materials And Methods \\ 2.1. Materials}

Corn starch with $10 \%$ moisture and the amylose/amylopectin ratio of 0.3 was supplied by Glucosan Inc. (Qazvin, Iran). General purpose polystyrene GPPS1160 with melt flow index (MFI) of $2.5 \mathrm{~g} / 10 \mathrm{~min}$ at $200^{\circ} \mathrm{C}$, was purchased from Tabriz Petrochemical Co. Ltd. (Tabriz, Iran). Citric acid and sodium bicarbonate (SB) were obtained from DaeJung Corporation (Shiheung, South Korea). Talc as nucleating agent was also purchased from Omya Pars Co. (Tehran, Iran). Glycerol was supplied by a local company. Double-distilled water was used to control the moisture content of starch in TPS preparation procedure, as well.

\subsection{Fabrication of TPS/PS blend Foam 2.2.1. Preparation of TPS}

TPS was prepared with different plasticizer amounts of $\mathrm{G}+\mathrm{W}$ (glycerol and water was symbolized with $\mathrm{G}$ and $W$, respectively), i.e. 21, 23, 25 and $29 \mathrm{wt} \%$ at various $W / G$ ratios, i.e. $1 / 2,2 / 3,3 / 2$ and $2 / 1$. For chemical modification of native starch, $2 \mathrm{wt} \%$ citric acid was used to partially esterify the starch for better heat stabilization [27]. The action was implemented to reduce the crystallinity degree of starch via the decrement of hydrogen bonding amount between the chains [28]. Because, the crystals act as an 
obstacle against the starch processing [29] According to the presented formulation in Table 1, these materials were mixed in a high-speed dry mixer for $4 \mathrm{~min}$. In order to penetrate the plasticizers into starch, the mixed powders were kept for $48 \mathrm{~h}$ in ambient temperature. Afterward, the mixtures were processed in a lab-scale single screw extruder, KEX series, L/D ratio of 26 made by KAJARAN Company (Iran). The barrel temperature for feeding and die zones were 95 and $120^{\circ} \mathrm{C}$, respectively, and the screw speed was adjusted $30 \mathrm{rpm}$. The obtained TPSs were pelletized for better blending with PS.

Table 1

Designed formulations for TPS preparation. The TPS samples were symbolized with $\mathrm{Sx}-\mathrm{y}$, in which $\mathrm{x}$ is the $\mathrm{G}+\mathrm{W}$ amount of 21 , 23,25 and $29 \%$, and $y$ is the $W / G$ ratio of $1 / 2,2 / 3,3 / 2$ and $2 / 1$, respectively.

\begin{tabular}{|c|c|c|c|c|}
\hline Sample & $\begin{array}{l}\text { Starch } \\
(w t \%)\end{array}$ & $G^{*}+W^{*}(w t \%)$ & Citric acid (wt\%) & $W^{*} / G^{*}$ \\
\hline$S 21-1 / 2$ & 77 & 21 & 2 & $1 / 2$ \\
\hline$S 21-2 / 3$ & 77 & 21 & 2 & $2 / 3$ \\
\hline$S 21-3 / 2$ & 77 & 21 & 2 & $3 / 2$ \\
\hline S21-2/1 & 77 & 21 & 2 & $2 / 1$ \\
\hline S23-1/2 & 75 & 23 & 2 & $1 / 2$ \\
\hline S23-2/3 & 75 & 23 & 2 & $2 / 3$ \\
\hline$S 23-3 / 2$ & 75 & 23 & 2 & $3 / 2$ \\
\hline$S 23-2 / 1$ & 75 & 23 & 2 & $2 / 1$ \\
\hline$S 25-1 / 2$ & 73 & 25 & 2 & $1 / 2$ \\
\hline$S 25-2 / 3$ & 73 & 25 & 2 & $2 / 3$ \\
\hline S25-3/2 & 73 & 25 & 2 & $3 / 2$ \\
\hline S25-2/1 & 73 & 25 & 2 & $2 / 1$ \\
\hline S29-1/2 & 69 & 29 & 2 & $1 / 2$ \\
\hline S29-2/3 & 69 & 29 & 2 & $2 / 3$ \\
\hline$S 29-3 / 2$ & 69 & 29 & 2 & $3 / 2$ \\
\hline S29-2/1 & 69 & 29 & 2 & $2 / 1$ \\
\hline
\end{tabular}

*: G and W represent glycerol and water contents, respectively.

\subsubsection{Preparation of TPS/PS blend Foam}


First, the prepared Sx-y samples in Sect. 2.2.1, were blended with PS at the TPS/PS blend ratio of 40/60 via using the extruder. The temperatures for feeding and die zones set equal to 95,160 and $165^{\circ} \mathrm{C}$, respectively. In addition, the speed of rotation was $30 \mathrm{rpm}$. Then, in order to produce the TPS/PS blend foams, talc, and a combination of SB [30] and citric acid (as foaming agent) were added to the prepared pelletized blends. Next, according to the presented formulations in Table 2, the blend foams were manufactured by extruding pre-mixtures using the same extruder with the process conditions similar to the blend preparation.

Table 2

Designed formulations for TPS/PS blend foam with the ratio of $40 / 60$ via the plasticized Sx-y samples (Table 1). The samples of TPS/PS blend foams were symbolized by Fx-y, in which $x$ and $y$ belong to Sx-y.

\begin{tabular}{|llll|}
\hline Sample & TPS/PS & FA $^{*}$ (wt\%) & Talc (wt\%) \\
\hline F21-1/2 & $(\mathrm{S} 21-1 / 2) 40 / 60$ & 2 & 0.5 \\
\hline F21-2/3 & $(\mathrm{S} 21-2 / 3) 40 / 60$ & 2 & 0.5 \\
\hline F21-2/1 & $(\mathrm{S} 21-2 / 1) 40 / 60$ & 2 & 0.5 \\
\hline F23-1/2 & $(\mathrm{S} 23-1 / 2) 40 / 60$ & 2 & 0.5 \\
\hline F23-2/3 & $(\mathrm{S} 23-2 / 3) 40 / 60$ & 2 & 0.5 \\
\hline F23-3/2 & $(\mathrm{S} 23-3 / 2) 40 / 60$ & 2 & 0.5 \\
\hline F23-2/1 & $(\mathrm{S} 23-2 / 1) 40 / 60$ & 2 & 0.5 \\
\hline F25-1/2 & $(\mathrm{S} 25-1 / 2) 40 / 60$ & 2 & 0.5 \\
\hline F25-2/3 & $(\mathrm{S} 25-2 / 3) 40 / 60$ & 2 & 0.5 \\
\hline F25-3/2 & $(\mathrm{S} 25-3 / 2) 40 / 60$ & 2 & 0.5 \\
\hline F25-2/1 & $(\mathrm{S} 25-2 / 1) 40 / 60$ & 2 & 0.5 \\
\hline F29-1/2 & $(\mathrm{S} 29-1 / 2) 40 / 60$ & 2 & 0.5 \\
\hline F29-2/3 & $(\mathrm{S} 29-2 / 3) 40 / 60$ & 2 & 0.5 \\
\hline F29-3/2 & $(\mathrm{S} 29-3 / 2) 40 / 60$ & 2 & 0.5 \\
\hline F29-2/1 & $(\mathrm{S} 29-2 / 1) 40 / 60$ & 2 & 0.5 \\
\hline
\end{tabular}

*: FA indicates the combination of SB and citric acid as a foaming agent. 
SEM image was taken from the cross section surface of the Fx-y samples by TESCAN Vega II, Czech Republic, using an accelerating voltage of $30 \mathrm{kV}$. All the Fx-y samples were firstly frozen in liquid nitrogen then snapped and followed by vacuum-dried. Before observation, the samples were coated with a thin layer of gold. The test was performed to quantitate the cell characteristics of the foams.

The volume expansion ratio (VER), cell density $\left(\mathrm{N}_{\mathrm{c}}\right)$ and its wall thickness $(\delta)$, as follows: [31-33]

$$
\begin{aligned}
& \text { VER }=\rho_{\mathrm{p}} / \rho_{\mathrm{f}} \\
& \mathrm{N}_{\mathrm{c}} \cong \frac{10^{4}}{\mathrm{~d}_{\mathrm{a}}^{\mathrm{g}}}\left[1-\frac{1}{\mathrm{VER}}\right] \\
& \delta=\mathrm{d}_{\mathrm{a}}\left[\frac{1}{\sqrt{1-\frac{1}{\mathrm{VER}}}}-1\right]
\end{aligned}
$$

where $p_{f}$ and $p_{p}$ are the foam and pre-foamed densities for each sample, respectively.

\subsubsection{Density measurement}

In this work, a basic method [33] was used to determine the density of each Fx-y and its pre-foamed blend, the sample's mass divided by its volume. The densities were obtained with an average on 5 different specimens for each foam and pre-foamed sample.

\subsubsection{Moisture absorption}

To determine hydrophilicity level of the Fx-y foams, 5 pre-dried specimens for each formulation were weighed with a sensitive scale and then were placed in the condition of $76 \%$ relative humidity (RH) for $192 \mathrm{~h}$. After the period, the samples were again weighed, and moisture absorption amount (MA) was calculated.

\section{Results And Discussions}

\subsection{Structure and physical properties of foams}

In this research work, the results were discussed with respect to the influence of $G+W$ and W/G amounts on microstructural and physical properties of Fx-y foams, to find an optimized formulation for TPS/PS blend foam. Fabricated Fx-y samples with various amount of plasticizers, $x$, at different $y$ ratios were shown in Fig. 1.

SEM images of TPS/PS (40/60) blend foams with various plasticizer contents of $\mathrm{G}+\mathrm{W}$ and ratios of $W / G$ are demonstrated in Fig. 2. As seen in the figure, using lower amount of plasticizer at the TPS preparation helps to achieve a foam with better morphology. Moreover, increasing y from $1 / 2$ to $2 / 1$, caused a better distribution for the foams cellules at the lower amount of $x$. Therefore, increasing and 
decreasing the contents of glycerol and water in the plasticizer combination, respectively, damaged the cells structure and led to a further cell collapse. Since, in spite of the plasticization role, evaporation of water has favorable influence on foaming in the extruder process, from blowing aspect. While, glycerol with a much higher boiling point [34] than the process temperature, acted as a plasticizer only, and caused the reduction of blend melt viscosity. The increment of plasticizer content $(x)$ led to the collapse of foam cells. The worst effect of plasticizer on the blend foam belonged to F23-y and F25-y samples, which significant cell wall rupture was observed in them. It can be attributed to lower melt strength of the Fx-y blend foams compared to the enhancement of the gas pressure within extruder barrel, due to the increase of water vapors. This issue causes rupturing the wall of created bubbles during the foaming process, and subsequently the foam collapse. Accordingly, the effect of raising y had an opposite influence on the cells structure in the F23-y and F25-y samples, due to the surplus made internal pressure by water vapors, and followed by rupturing the cells wall. Because, TPS with these levels of plasticization could not endure the bubble internal pressure. Therefore, cell wall rupture occurred for F23-y and F25-y samples, particularly at higher $y$. In addition, enhancing the plasticizer amount to $x=29 \%$ changed the aforementioned variation trend, due to further reduction of crystallinity degree and hydrogen bonding between the starch chains compared to $x=23$ and $25 \%$. In fact, this issue increased the melt strength [24] of the F29-y samples that helped saving the created cells, subsequently, this issue obliged the cells to endure even higher amount of water vapors at further $y$ values.

According to Fig. 2, the cellular structure of Fx-y samples did not have any regularity, and included of large and small bubbles. In order to create a deep insight into the plasticizer effect on the microstructural properties of Fx-y, first, the cells diameter of each Fx-y sample was obtained via using SEM images. After that, the probability density function (PDF) of the cells diameters was computed for all the foam samples and then were shown in Fig. 3. As discussed currently, increasing the $x$ and $y$ contents in F21-y and F29-y had a favorable effect on the cell size, with taller and slender distributions at less amounts of $d$ (see Fig. 3). Whereas, this behavior was completely vice versa in the F23-y and F25-y samples.

The achieved cell characteristics of each Fx-y sample are listed in Table 3. As seen in the table, the calculated results of cell size (d) and standard deviation $(\sigma)$ have a good conformity with Fig. 2 and Fig. 3 , and verifies the mentioned discussions on the irregularity of foam cellules, clearly. According to the results, increasing the loading content of water in the plasticizer combination led to enhancing the cell density in F21-y and F29-y. Whereas, the behavior was inverse in the F23-y and F25-y samples. Besides, cell wall thickness did not have a specified variation. Moreover, the VER values of F21-y and F29-y samples nearly had an irrespective behavior to $y$, while, its evolution was uptrend in F23-y and F25-y. Since, the cell rupture occurred in the foams with $x=23$ and $25 \%$ leading to increasing the cell size significantly (see Figs. 2 and 3). This issue raised the volume of mentioned foams compared to the foams with $x=21$ and $29 \%$. 
Table 3

Cell characteristics of Fx-y blend foams.

\begin{tabular}{|lllll|}
\hline Sample & $\begin{array}{l}\mathrm{d} \pm \sigma \\
(\mathrm{mm})\end{array}$ & VER & $\begin{array}{l}\mathrm{N}_{\mathrm{c}} \\
\left(\mathrm{cell} / \mathrm{mm}^{3}\right)\end{array}$ & $\begin{array}{l}\boldsymbol{\delta} \\
(\mathrm{mm})\end{array}$ \\
\hline F21-1/2 & $0.283 \pm 0.097$ & 1.990 & $2.195 \times 10^{5}$ & 0.118 \\
\hline F21-2/3 & $0.339 \pm 0.152$ & 1.708 & $1.064 \times 10^{5}$ & 0.187 \\
\hline F21-3/2 & $0.197 \pm 0.108$ & 1.587 & $4.838 \times 10^{5}$ & 0.127 \\
\hline F21-2/1 & $0.197 \pm 0.073$ & 1.296 & $2.991 \times 10^{5}$ & 0.215 \\
\hline F23-1/2 & $0.873 \pm 0.401$ & 1.696 & $0.061 \times 10^{5}$ & 0.489 \\
\hline F23-2/3 & $0.577 \pm 0.334$ & 3.065 & $0.350 \times 10^{5}$ & 0.126 \\
\hline F23-3/2 & $0.402 \pm 0.222$ & 5.253 & $1.246 \times 10^{5}$ & 0.044 \\
\hline F23-2/1 & $0.678 \pm 0.396$ & 6.427 & $0.271 \times 10^{5}$ & 0.059 \\
\hline F25-1/2 & $0.119 \pm 0.051$ & 1.489 & $19.500 \times 10^{5}$ & 0.088 \\
\hline F25-2/3 & $0.230 \pm 0.072$ & 1.755 & $3.537 \times 10^{5}$ & 0.120 \\
\hline F25-3/2 & $0.323 \pm 0.184$ & 2.981 & $1.972 \times 10^{5}$ & 0.073 \\
\hline F25-2/1 & $0.491 \pm 0.212$ & 5.167 & $0.681 \times 10^{5}$ & 0.055 \\
\hline F29-1/2 & $0.254 \pm 0.095$ & 1.580 & $2.242 \times 10^{5}$ & 0.165 \\
\hline F29-2/3 & $0.326 \pm 0.196$ & 1.535 & $1.006 \times 10^{5}$ & 0.225 \\
\hline F29-3/2 & $0.196 \pm 0.093$ & 1.950 & $6.472 \times 10^{5}$ & 0.084 \\
\hline F29-2/1 & $0.124 \pm 0.062$ & 1.745 & $22.397 \times 10^{5}$ & 0.065 \\
\hline
\end{tabular}

To create a better view into the density variation of Fx-y foams with changing the plasticizer contents and combinations, foam density at various $x$ and water percentage in plasticizer combination ( $z$ ) were reported in Fig. 4. As shown in Fig. 4a, density of F21-y and F29-y have a smooth change with increasing the $z$ value, while this change is rapidly in F23-y and F25-y. This issue is due to the uniform distribution, and integration of bubbles in the F21,29-y and F23,25-y foams, respectively. Therefore, a main factor of the decrement of foam density of F23,25-y, was the cell rupture and followed by agglomeration of the bubbles. Additionally, Fig. $4 \mathrm{~b}$ shows the density change versus plasticizer content at a same z. As shown, after engendering a minimum in the curve, the foam density increased with increasing $x$ at diverse amount of $z$. higher amount of water content in plasticizer combination caused a lower value for $\rho_{f}$. 


\subsection{Water absorption property}

TPS is a water soluble polymer due to its numerous hydroxyl groups [29], which leads to moisture attack and followed by significant changes in its physical and mechanical properties [36]. Moreover, the hydrophilicity reduces the TPS tendency to its hydrophobic counterpart, like PS, in polymer blending [37] Accordingly, this issue limits the TPS usage in industrial applications. In this work, we considered the effect of different plasticizer contents and combinations on the moisture absorption of TPS/PS blend foam with the ratio of 40/60. The obtained MA versus $z$ and $x$ for each Fx-y sample was reported in Fig. $5 a$ and $b$, respectively. As exhibited in the figure, MA value reduced with increasing the $z$ amount at each $x$, and as well as raising the $x$ content led to the reduction and then enhancement of MA at each $z$. Factually, the increment of $z$ had an extreme effect to increase the hydrophobicity of the blend foam. Because, rising the water content in plasticizer leading to reduction of the intermolecular hydrogen bonding between the starch chains via frustrating the chains' $\mathrm{OH}$ groups [38]. In contrast, increasing glycerol in the plasticizer combination have an undesirable effect on the hydrophilicity reduction of the blend foam, due to its high water tendency [39].

\subsection{Statistical data analysis}

In order to find an optimized formulation for TPS/PS blend foam from plasticizer point of view, $4 \times 4$ full factorial design was used. This consideration was carried out to achieve a blend foam with the most desirable microstructural and moisture absorption properties. Design of experiment (DOE) and analysis of variance (ANOVA) were applied via utilizing MINITAB ${ }^{8} 18$ [40]. The plasticizer contents of $x=21,23$, $25,29 \%$, and water percentage in plasticizer combination of $z=33.3,40,60,66.7 \%$, were evaluated as the independent factors, cell diameter and water absorption amounts were also defined as the responses in DOE. Factually, all the microstructural properties and hydrophobicity behaviors of the blend foams are the function of these two responses. The responses were investigated in five replications. After removing of non-significance items, the fitted models provided by the mentioned software for average cell diameter, $d_{a}$, and water absorption, MA. The results were reported in Table 4. The coefficients in each equation demonstrates the effect of the related term on that property. Positive and negative coefficients of the linear models indicate a synergistic and decreasing impact on the responses, respectively. In fact, the goal of optimization was to minimize cell diameter and foam ability to absorb moisture. Because, a TPS/PS blend foam with these characterizations leads to the best microstructural and hydrophobicity properties (see Sect. 3.1). 
Table 4

Linear model for average cell diameter and moisture absorption of the TPS/PS blend foams with the ratio of $40 / 60 . x$ and $z$ are the plasticizer content and water percentage in the plasticizer combination.
Response Linear model
Cell $\quad d=0.3483-0.09431 \times[21]+0.2752 \times[23]-0.05756 \times[25]-0.1233 \times[29]+0.02494 z$
diameter $\quad[33.3]+0.01969 \mathrm{z}[40.0]-0.06881 \mathrm{z}[60.0]+0.02419 \mathrm{z}[66.7]+0.004062 \mathrm{x} \times \mathrm{z}$
$[21,33.3]+0.06531 x \times z[21,40.0]+0.01181 x \times z[21,60.0]-0.08119 x \times z[21,66.7]$
$+0.1886 x \times z[23,33.3]-0.06619 x \times z[23,40.0]-0.1527 x \times z[23,60.0]+0.03031 x \times z[23$
$66.7]-0.1967 \mathrm{x} \times \mathrm{z}[25,33.3]-0.08044 \mathrm{x} \times \mathrm{z}[25,40.0]+0.1011 \mathrm{x} \times \mathrm{z}[2560.0]+0.1761 \mathrm{x} \times \mathrm{z}$
$[25,66.7]+0.004063 x \times z[29,33.3]+0.08131 x \times z[29,40.0]+0.03981 x \times z[29,60.0]$
$-0.1252 x \times z[29,66.7]$
Moisture
absorption
$M A=4.6250-0.012 \times[21]-0.640 \times[23]+0.112 \times[25]$
$+0.540 x[29]+0.735 z[33.3]+0.613 z[40.0]-0.600 z$ [60.0]- $0.748 z$ [66.7]

Further, desirability function approach (D) was used at the optimization process of the results. It is based on transforming $\mathrm{d}$ and MA into a desirability values, the combination of individual responses into a composite function and then its optimization [41]. The $D$ values were so close to 1 , which indicates the efficient settings to obtain desirable results for $d$ and MA [42]. Finally, $x=21 \%$ and $z=66.7 \%(y=2 / 1)$ was obtained from optimization process (see Fig. 6) to produce the optimum level of microstructural and hydrophobicity properties for TPS/PS blend foam.

\subsection{Effect of PS content on the TPS/PS foam properties}

To investigate the impact of TPS loading content on the microstructural, physical and moisture absorption properties of the TPS/PS blend foams, the optimized TPS ( $x=21 \%$ and $z=66.7 \%$ or $y=2 / 1$ ) was used. For this purpose, TPS/PS foam with the PS percentage of $0,20,40,60,80$ and $100 \%$ was supplied via presented methodology in Sect. 2.2.2. The TPS/PS blend foam with different amount of PS was symbolized with Fr, in which $r$ is the PS percentage. The created foam with different $r$ was shown in Fig. 7.

To create a deep understanding into the impact of TPS content on the microstructural properties of the blend foam, SEM images were taken from the Fr samples. Moreover, cells diameter was estimated from the SEMs and their PDF was drawn for each sample. The SEM and PDF achievements were reported in Fig. 8 together.

As shown in Fig. 8, the blend foam at the absence of PS had a good cell morphology and uniform distribution of cell diameter. While, increasing the PS content led to widen the PDF curve and creation of the cell wall rupture, and followed by joining the bubbles together and then creation of very large cellules. This trend was inverse after $r>50 \%$. As seen in the figure, TPS/PS with the $r$ value of $80 \%$ has a good cell size, lower irregularity, and also probability density function with a slender distribution at a less amount of d. F100 (pure PS) had the slenderest PDF distribution and the furthest amount of probability at the least cell diameter, which was distinct already, due to the PS ability to foam [44]. To quantitate the cell and foams properties, $d, N_{c}, \rho_{f}$ and MA amounts were listed in Table 5. According to the table, F20 has efficient foam from i.e. cellular, physical, moisture absorption properties. This formulation has higher 
expansion ratio than TPS and PS with about half moisture absorption compared to TPS. This combination can be a good alternative candidate for pure PS foam packaging.

Table 5

Cell and foam characteristics for each Fr sample.

\begin{tabular}{|llllll|}
\hline Sample & $\begin{array}{l}\mathbf{d} \pm \sigma \\
(\mathrm{mm})\end{array}$ & $\begin{array}{l}\mathrm{N}_{\mathbf{c}} \\
\left(\mathrm{cell} / \mathrm{mm}^{3}\right)\end{array}$ & $\begin{array}{l}\delta \\
(\mathrm{mm})\end{array}$ & $\begin{array}{l}\text { VER } \\
\text { F0 }\end{array}$ & $\begin{array}{l}\text { MA } \\
(\%)\end{array}$ \\
\hline F20 & $0.169 \pm 0.063$ & $17.90 \times 10^{5}$ & 0.012 & 7.36 & 9.77 \\
\hline F40 & $0.883 \pm 0.247$ & $2.10 \times 10^{5}$ & 0.015 & 12.17 & 5.02 \\
\hline F60 & $0.197 \pm 0.073$ & $0.11 \times 10^{5}$ & 0.0994 & 5.18 & 4.83 \\
\hline F80 & $0.426 \pm 0.219$ & $0.66 \times 10^{5}$ & 0.166 & 2.07 & 2.11 \\
\hline F100 & $0.112 \pm 0.258$ & $30.96 \times 10^{5}$ & 0.057 & 1.77 & 0 \\
\hline
\end{tabular}

TPS had a negative effect on the cell growth and its diameter, which were randomly distributed. In fact, it can be attributed to the PS good response to the blowing agent in comparison with starch. In addition, the good melt strength of PS prevented the cell rupture, while this issue was vice versa in the TPS media.

\section{Conclusions}

In this research work, TPS/PS blend foam prepared by melt extrusion process was investigated at different plasticizer contents and combinations, and the blend ratio. The influence of content of water+ glycerol as plasticizer and as well as water/glycerol ratio on the foam microstructural and physical properties were studied at a same TPS/PS ratio of $40 / 60$. Plasticizer content was varied between $21 \%$ up to $29 \%(21,23,25$, and $29 \%)$ and water/glycerol ratios were $1 / 2,2 / 3,3 / 2$ and $2 / 1$. The results showed that the combination of plasticizer affects significantly on the cell properties of the blend foams. Moreover, a decrease in foam density was observed at the increment of the water content in plasticizer combination which the least foam density belonged to F23-2/ 1 sample.. The lowest density of 0.189 $\mathrm{g} / \mathrm{cm}^{3}$ and moisture absorption of $3.3 \%$ was obtained by plasticizers variations. In addition, the influence of plasticizer contents and combinations on the hydrophilicity behavior of the blend foam also evaluated. Moreover, the effect of various contents of PS in the blend showed the concentration of $20 \%$ PS caused to highest expansion ratio with low moisture absorption. The VER of this blend was about 6 times higher than PS and $60 \%$ higher than TPS.

\section{References}


1. Rizan C, Mortimer F, Stancliffe R, Bhutta MF, "Plastics in healthcare: time for a re-evaluation," J. $R$. Soc. Med., vol. 113, no. 2, pp. 49-53, Feb. 2020, doi: 10.1177/0141076819890554

2. Arrieta MP, Samper MD, López J, Jiménez A (2014) Combined effect of poly (hydroxybutyrate) and plasticizers on polylactic acid properties for film intended for food packaging. J Polym Environ 22(4):460-470

3. Vo CV, Bunge F, Duffy J, Hood L (May 2011) Advances in Thermal Insulation of Extruded Polystyrene Foams. Cell Polym 30(3):137-156. doi:10.1177/026248931103000303

4. Lickly TD, Lehr KM, Welsh GC (Jun. 1995) Migration of styrene from polystyrene foam food-contact articles. Food Chem Toxicol 33(6):475-481. doi:10.1016/0278-6915(95)00009-Q

5. Vroman I, Tighzert L, “Biodegradable Polymers," Materials (Basel)., vol. 2, no. 2, pp. 307-344, Apr. 2009, doi: $10.3390 /$ ma2020307

6. Rydz J, Sikorska W, Kyulavska M, Christova D (Dec. 2014) Polyester-Based (Bio)degradable Polymers as Environmentally Friendly Materials for Sustainable Development. Int J Mol Sci 16(1):564-596. doi:10.3390/ijms16010564

7. Wróblewska-Krepsztul J, Rydzkowski T, Borowski G, Szczypiński M, Klepka T, Thakur VK (May 2018) Recent progress in biodegradable polymers and nanocomposite-based packaging materials for sustainable environment. Int J Polym Anal Charact 23(4):383-395. doi:10.1080/1023666X.2018.1455382

8. Bhatnagar S, Hanna MA (1995) Physical, Mechanical, and Thermal Properties of Starch-Based Plastic Foams. Trans ASAE 38(2):567-571. doi:10.13031/2013.27867

9. Merino D, Gutiérrez TJ, Alvarez VA (2019) Potential agricultural mulch films based on native and phosphorylated corn starch with and without surface functionalization with chitosan. J Polym Environ 27:97-105

10. Lemos PVF, Barbosa LS, Ramos IG, Coelho RE, Druzian JI, “Characterization of amylose and amylopectin fractions separated from potato, banana, corn, and cassava starches," Int. J. Biol. Macromol., vol. 132, pp. 32-42, Jul. 2019, doi: 10.1016/j.ijbiomac.2019.03.086

11. Akrami M, Ghasemi I, Azizi H, Karrabi M, Seyedabadi M (2016) A new approach in compatibilization of the poly(lactic acid)/thermoplastic starch (PLA/TPS) blends. Carbohydr Polym 144:254-262. doi:10.1016/j.carbpol.2016.02.035

12. Zhang Y, Rempel C, Liu Q (Jan. 2014) Thermoplastic Starch Processing and Characteristics-A Review. Crit Rev Food Sci Nutr 54(10):1353-1370. doi:10.1080/10408398.2011.636156

13. Teixeira EM, Da Róz AL, Carvalho AJF, Curvelo AAS (2007) The effect of glycerol/sugar/water and sugar/water mixtures on the plasticization of thermoplastic cassava starch. Carbohydr Polym 69(4):619-624. doi:10.1016/j.carbpol.2007.01.022

14. García NL, Ribba L, Dufresne A, Aranguren M, Goyanes S (2011) Effect of glycerol on the morphology of nanocomposites made from thermoplastic starch and starch nanocrystals. Carbohydr Polym 84(1):203-210. doi:10.1016/j.carbpol.2010.11.024 
15. Liu XX et al (2014) Morphology and phase composition of gelatin-starch blends. Chinese J Polym Sci (English Ed. 32(1):108-114. doi:10.1007/s10118-014-1377-1

16. Da Róz AL, Zambon MD, Curvelo AAS, Carvalho AJF (2011) Thermoplastic starch modified during melt processing with organic acids: The effect of molar mass on thermal and mechanical properties. Ind Crops Prod 33(1):152-157. doi:10.1016/j.indcrop.2010.09.015

17. Volpe V, De Feo G, De Marco I, Pantani R, "Use of sunflower seed fried oil as an ecofriendly plasticizer for starch and application of this thermoplastic starch as a filler for PLA," Ind. Crops Prod., vol. 122, no. September 2017, pp. 545-552, 2018, doi: 10.1016/j.indcrop.2018.06.014

18. Huneault MA, Li H (Jan. 2007) Morphology and properties of compatibilized polylactide/thermoplastic starch blends. Polymer (Guildf) 48(1):270-280.

doi:10.1016/j.polymer.2006.11.023

19. Combrzyński M et al (May 2019) Effect of starch type and screw speed on mechanical properties of extrusion-cooked starch-based foams. Int Agrophysics 33(2):233-240. doi:10.31545/intagr/109517

20. Manepalli PH, Alavi S (2019) "Mathematical modeling of mechanical and barrier properties of poly (lactic acid)/poly (butylene adipate-co-terephthalate)/thermoplastic starch based nanocomposites. J Food Eng 261:60-65

21. Bhatnagar S, Hanna MA, Bhatnagar SS, Hanna MAMA (1995) Physical, mechanical, and thermal properties of starch-based plastic foams. Trans ASAE 38(2):567-571. doi:10.13031/2013.27867

22. Pushpadass HA, Weber RW, Dumais JJ, Hanna MA, "Biodegradation characteristics of starchpolystyrene loose-fill foams in a composting medium叉," Bioresour. Technol., vol. 101, no. 19, pp. 7258-7264, Oct. 2010, doi: 10.1016/j.biortech.2010.04.039

23. and Heartwin MAH, Pushpadass A, Weber RW (2008) Expansion, morphological, and mechanical properties of starch-polystyrene foams containing various additives. Ind Eng Chem Res 47(14):4736-4742. doi:10.1021/ie071049h

24. Mihai M, Huneault MA, Favis BD (May 2007) Foaming of Polystyrene/ Thermoplastic Starch Blends. J Cell Plast 43(3):215-236. doi:10.1177/0021955X07076532

25. Bhatnagar S, Hanna MA, "Properties of extruded starch-based plastic foam," Ind. Crops Prod., vol. 4, no. 2, pp. 71-77, Jul. 1995, doi: 10.1016/0926-6690(95)00016-6

26. Yayshahri AM, Peighambardoust SJ, Shenavar A (2019) Impact, thermal and biodegradation properties of high impact polystyrene / corn starch blends processed via melt extrusion. Polyolefins J 6(2):1-16. doi:10.22063/POJ.2019.2390.1130

27. Jiugao Y, Ning W, Xiaofei M, "The Effects of Citric Acid on the Properties of Thermoplastic Starch Plasticized by Glycerol," Starch - Stärke, vol. 57, no. 10, pp. 494-504, Oct. 2005, doi: $10.1002 /$ star.200500423

28. Ma X, Chang PR, Yu J, Stumborg M (2009) Properties of biodegradable citric acid-modified granular starch/thermoplastic pea starch composites. Carbohydr Polym 75(1):1-8.

doi:10.1016/j.carbpol.2008.05.020 
29. Mohammadi Nafchi A, Moradpour M, Saeidi M, Alias AK, "Thermoplastic starches: Properties, challenges, and prospects," Starch - Stärke, vol. 65, no. 1-2, pp. 61-72, Jan. 2013, doi:

10.1002/star.201200201

30. Abinader G, Lacoste C, Le Baillif M, Erre D, Copinet A (2015) Effect of the formulation of starch-based foam cushions on the morphology and mechanical properties. J Cell Plast 51(1):31-44. doi:10.1177/0021955X14527979

31. Nam PH et al (2002) Foam processing and cellular structure of polypropylene/clay nanocomposites. Polym Eng Sci 42(9):1907-1918. doi:10.1002/pen.11083

32. Mahmoudi Yayshahri A, Peighambardoust SJ, Shenavar A (2019) Impact, thermal and biodegradation properties of high impact polystyrene/corn starch blends processed via melt extrusion. Polyolefins J 6(2):151-158

33. Kahvand F, Fasihi M (2020) Microstructure and physical properties of thermoplastic corn starch foams as influenced by polyvinyl alcohol and plasticizer contents. Int J Biol Macromol 157:359-367. doi:10.1016/j.ijbiomac.2020.04.222

34. Morrison LR (2000) "Glycerol. In: " in Kirk-Othmer Encyclopedia of Chemical Technology. Wiley 35. Mahmoud MA, Henderson GR, Epprecht EK, Woodall WH, “Estimating the Standard Deviation in Quality-Control Applications," J. Qual. Technol., vol. 42, no. 4, pp. 348-357, Oct. 2010, doi: 10.1080/00224065.2010.11917832

36. Sjöqvist M, Boldizar A, Rigdahl M (2010) Processing and water absorption behavior of foamed potato starch. J Cell Plast 46(6):497-517. doi:10.1177/0021955X10377802

37. Kalambur S, Rizvi SSH (2006) An overview of starch-based plastic blends from reactive extrusion. J Plast Film Sheeting 22(1):39-58. doi:10.1177/8756087906062729

38. Sjöqvist M, Boldizar A, Rigdahl M (2009) Processing and properties of expanded starch materials. J Cell Plast 45(1):51-66. doi:10.1177/0021955X08099934

39. Yu JH, Wang JL, Wu X, Zhu PX, "Effect of glycerol on water vapor sorption and mechanical properties of starch/clay composite films," Starch/Staerke, 60, no. 5. 257-2622008, doi:10.1002/star.200700695

40. Mathews PG (2005) Design of Experiments with MINITAB. ASQ Quality Press Milwaukee, WI, USA:

41. Candioti LV, De Zan MM, Cámara MS, Goicoechea HC (2014) Experimental design and multiple response optimization. Using the desirability function in analytical methods development. Talanta 124:123-138

42. Daneshpayeh S, Ghasemi FA, Ghasemi I, Ayaz M (2016) Predicting of mechanical properties of PP/LLDPE/TiO2 nano-composites by response surface methodology. Compos Part B Eng 84:109120

43. Pourrahmani H, Golparvar M, Fasihi M (2020) A New Evaluation Criterion for Optimizing the Mechanical Properties of Toughened Polypropylene/Silica Nanocomposites. Chinese J Polym Sci (English Ed 38(8):877-887. doi:10.1007/s10118-020-2399-5 
44. Zhang C, Zhu B, Lee LJ, "Extrusion foaming of polystyrene/carbon particles using carbon dioxide and water as co-blowing agents," Polymer, 52, no. 8. 1847-18552011, doi:10.1016/j.polymer.2011.02.016

\section{Figures}

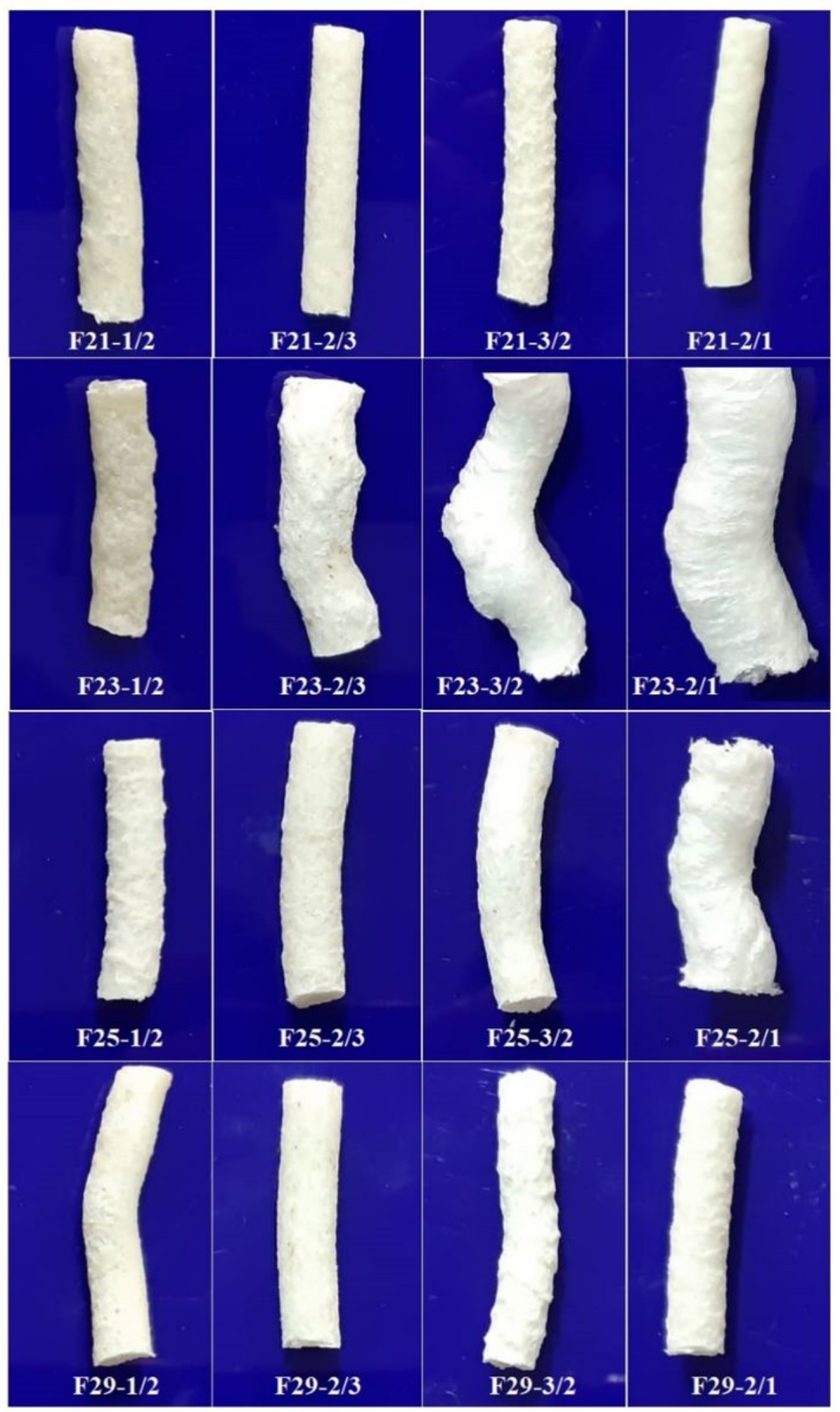

Figure 1 
Fx-y blend foams with TPS/PS blend ratio of 40/60 at different $x$ and $y$ amounts.

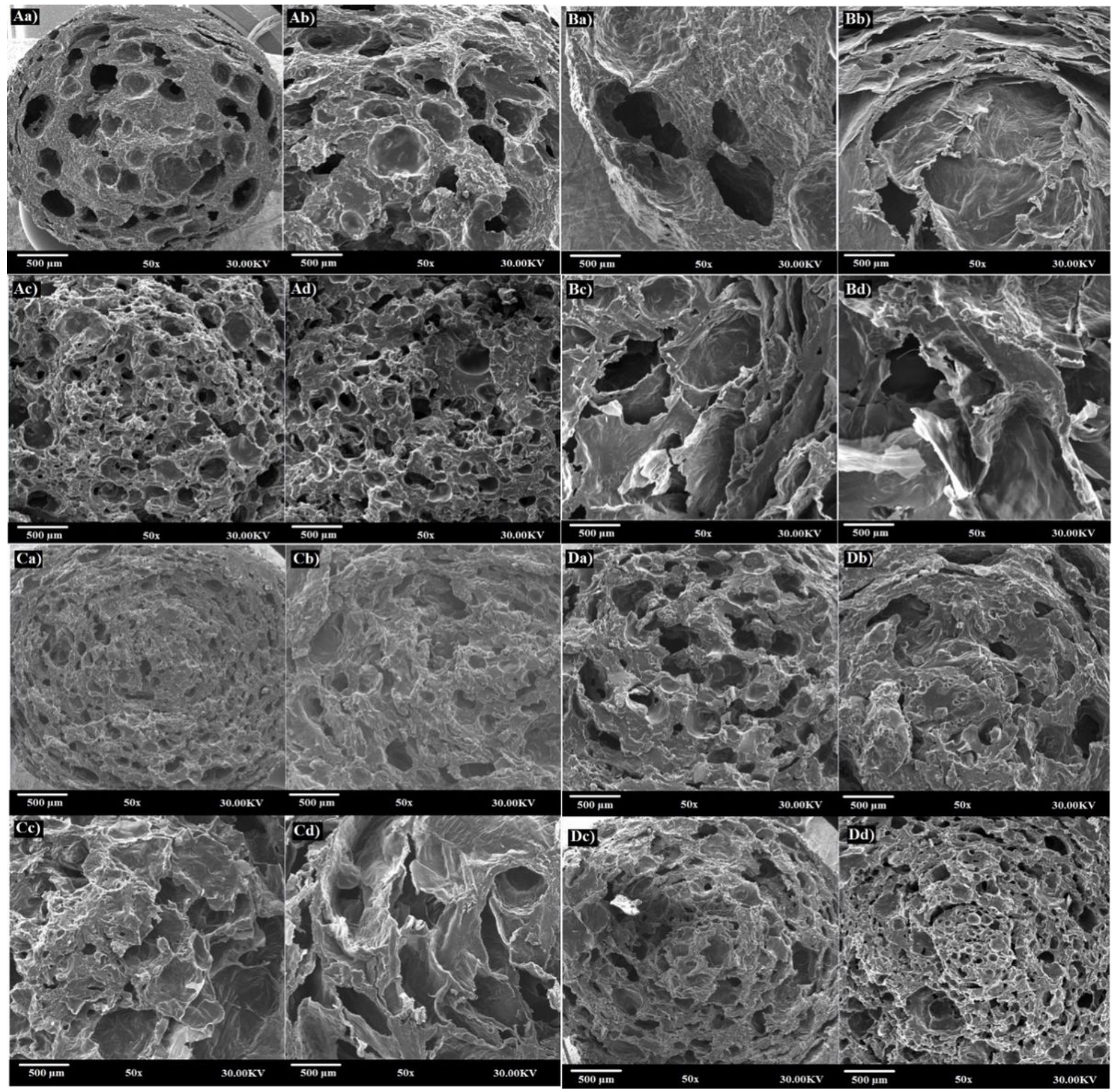

\section{Figure 2}

SEM micrographs of TPS/PS (40/60) blend foams with $x$ of A) $21 \%, B) 23 \%$, C) $25 \%$ and D) $29 \%$ at y amounts of a) $1 / 2$, b) $2 / 3$, c) $3 / 2$ and d) $2 / 1$, respectively. 


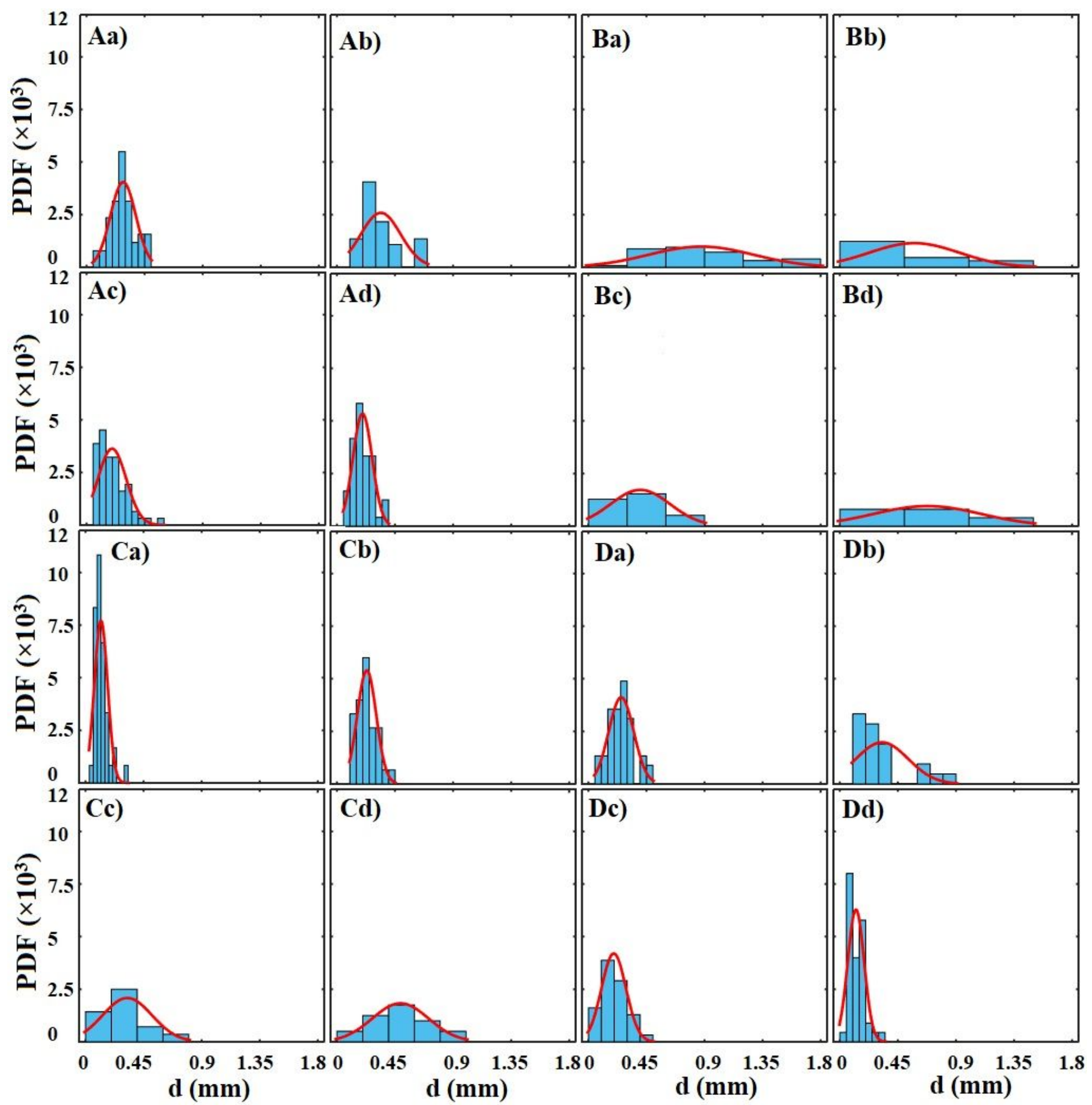

Figure 3

Probability density function (PDF) of cells diameters, d, for Fx-y with A) $x=21 \%, B$ ) $23 \%$, C) $25 \%$ and D) $29 \%$ at the amount of a) $y=1 / 2$, b) $y=2 / 3$, c) $y=3 / 2$ and d) $y=2 / 1$, respectively. 

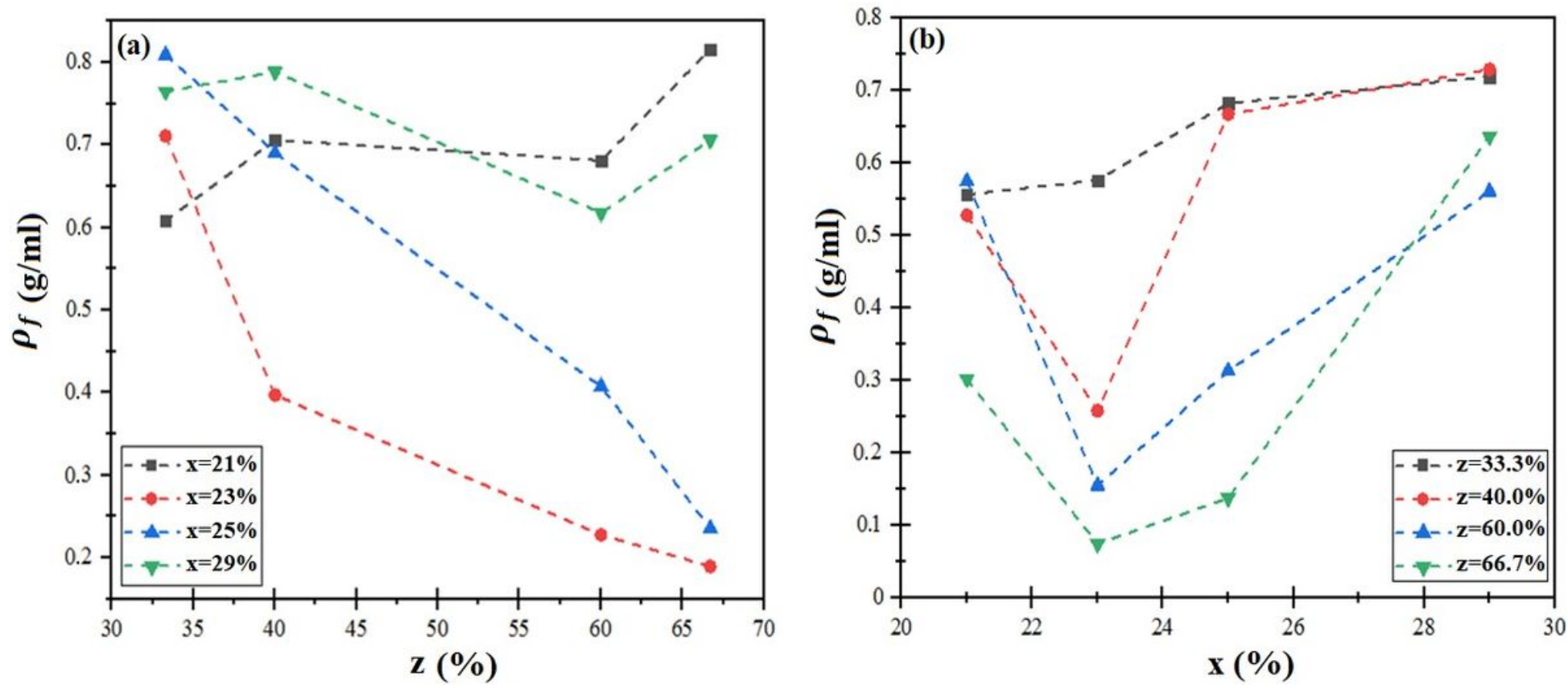

Figure 4

Density of Fx-y samples against (a) water percentage in plasticizer combination and (b) plasticizer content, respectively.
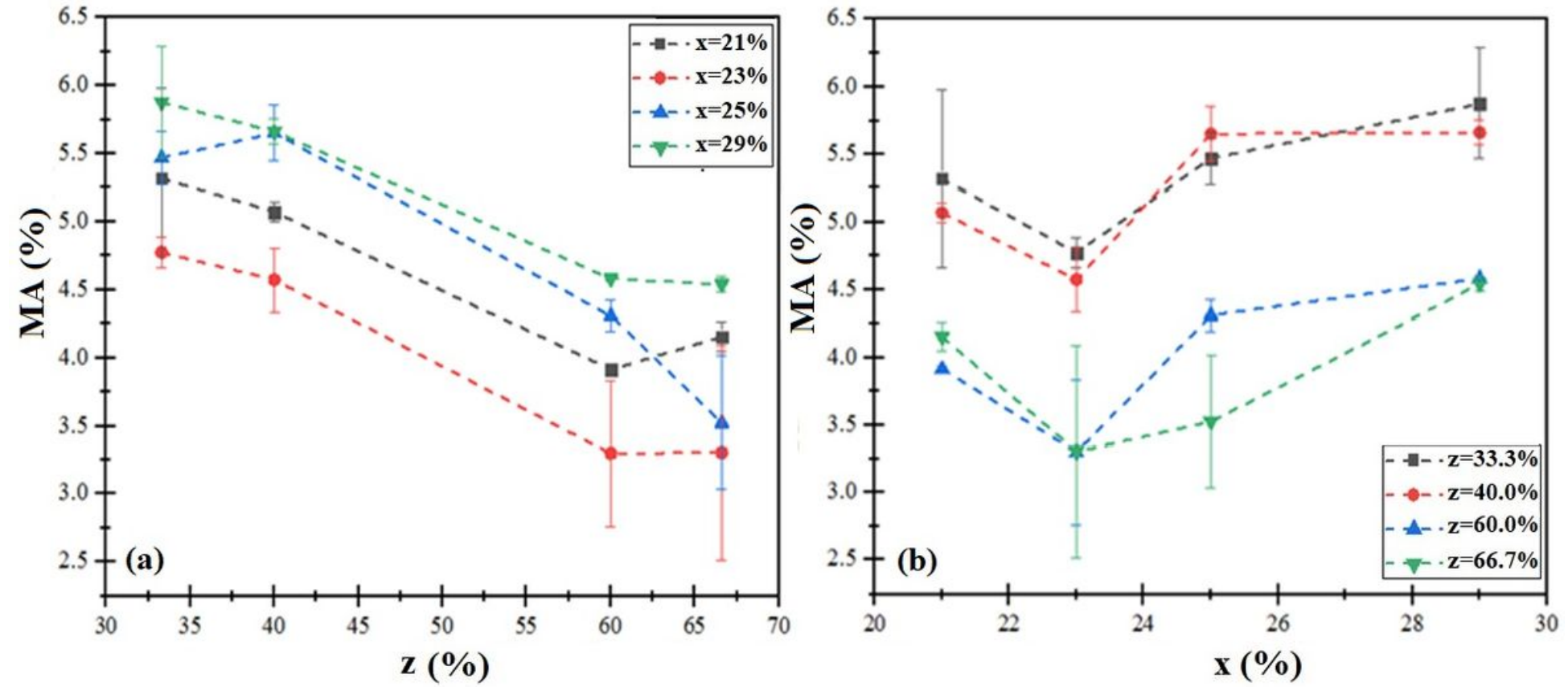

Figure 5

Moisture absorption (MA) amount of Fx-y samples versus (a) water percentage in plasticizer combination and (b) plasticizer content, respectively. 


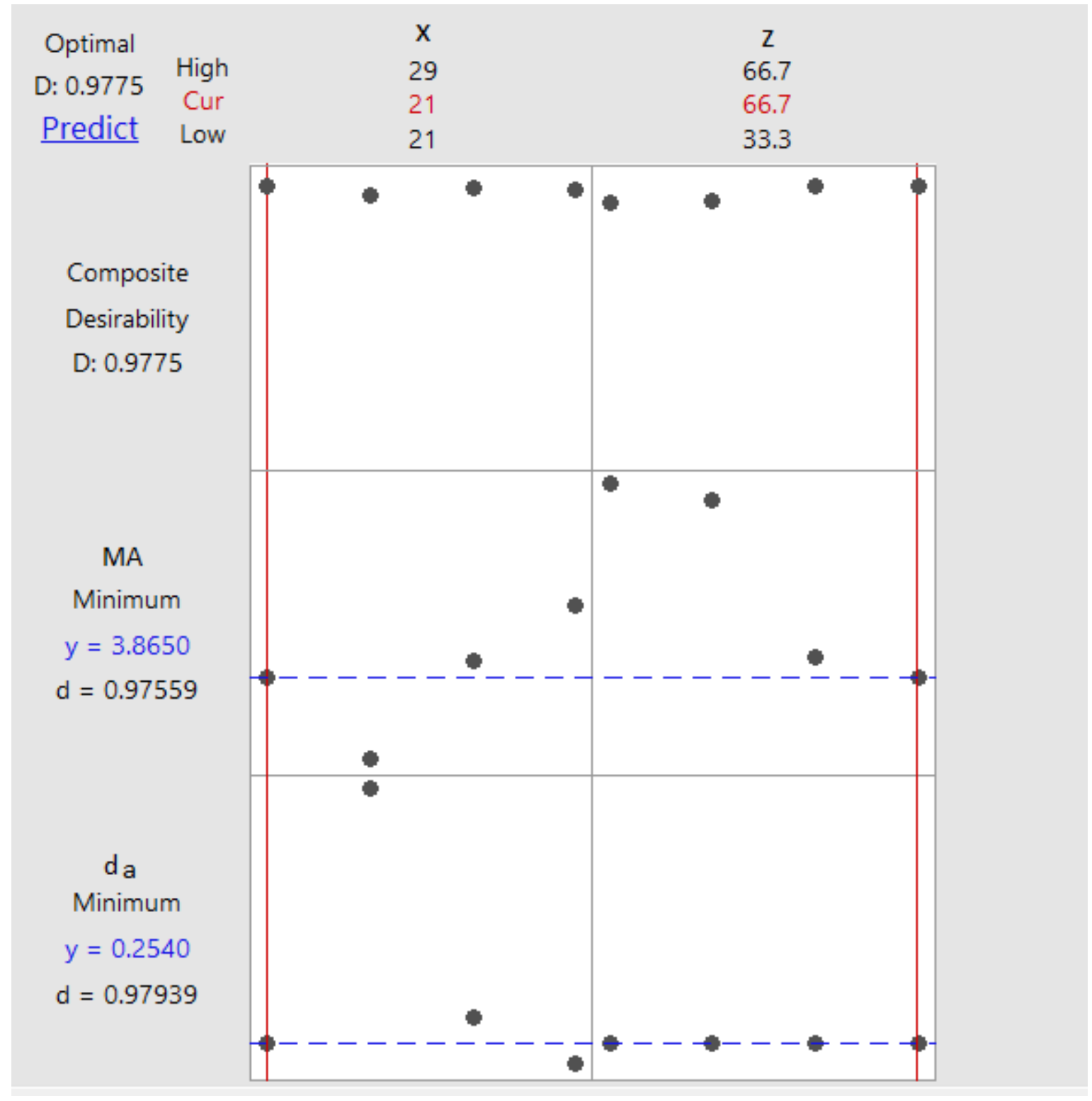

Figure 6

Optimization plot for the responses. 


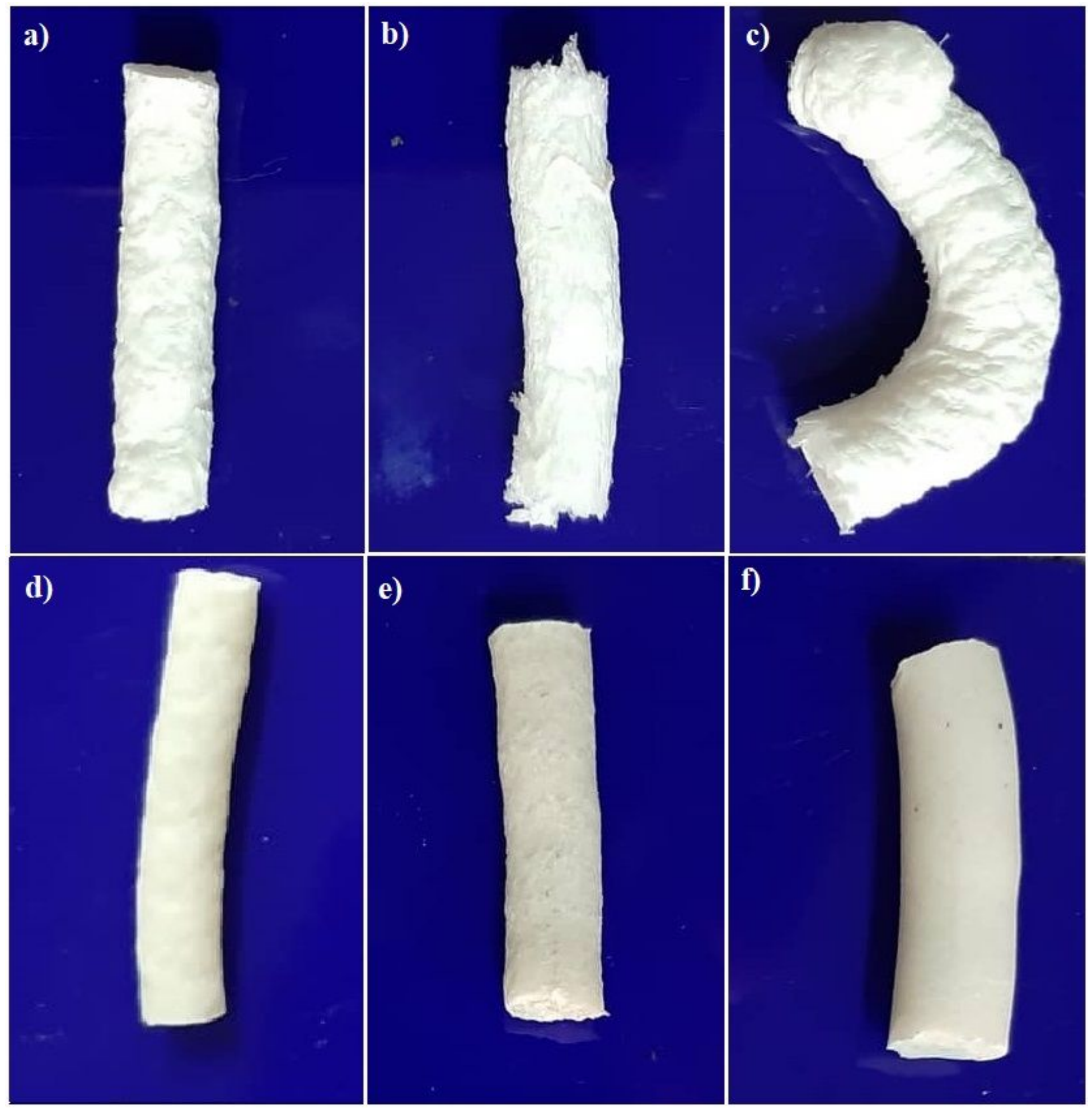

Figure 7

TPS/PS blend foam with the optimized formulation of TPS. (a) F0, (b) F20, (c) F40, (d) F60, (e) F80 and (f) F100. 


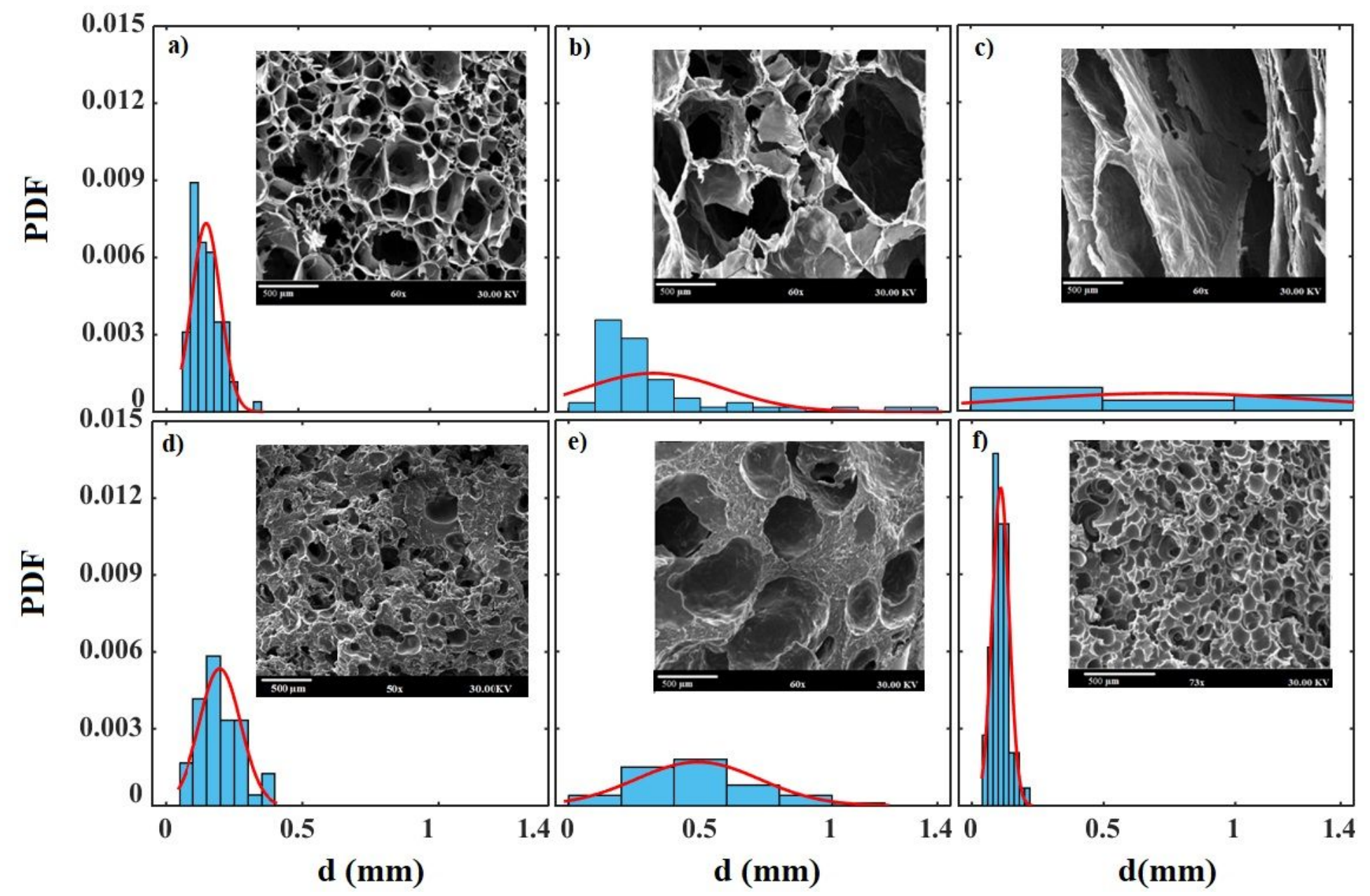

Figure 8

SEM images with the probability density function (PDF) of cells diameters for (a) F0, (b) F20, (c) F40, (d) F60, (e) F80 and (f) F100 samples. 